\title{
Desenvolvimento local e economia solidária: a experiência da Incubadora de Empreendimentos Solidários da UFOP (INCOP)
}

\section{Wagner Ragi Curi Filho}

Universidade Federal de Ouro Preto | Brasil

wagner@deenp.ufop.br

\section{Jean Carlos Machado Alves}

Universidade Federal de Ouro Preto | Brasil jean.mep@gmail.com

\section{Fernanda Faria Silva}

Universidade Federal de Ouro Preto | Brasil fernandaicsa@gmail.com

\section{Francisca Diana Ferreira Viana}

Universidade Federal de Ouro Preto | Brasil dianaufu@gmail.com

\section{Resumo}

O objetivo deste trabalho é discutir alguns entraves e oportunidades relacionados às estratégias de desenvolvimento local, a partir do papel das incubadoras de empreendimentos solidários. Tais iniciativas são importantes para consolidar as relações entre a universidade e a comunidade na qual está inserida, além de favorecer uma maior interação entre grupos sociais marginalizados e o seu milieu local, valorizando os princípios participativos, de autogestão, de empoderamento e de emancipação. Foram resgatados elementos conceituais sobre desenvolvimento local e economia solidária, e, por fim, apresentado como estudo de caso o projeto de extensão da INCOP - UFOP.

\section{Palavras-chave}

Desenvolvimento local; Economia solidária; INCOP UFOP. 


\section{Introdução}

A inflexão político - econômica e institucional da década de 1980 provocou mudanças importantes na forma de se pensar o papel do Estado, tendo reflexos sobre as estratégias de desenvolvimento regional e local, forjando o surgimento de formas alternativas de arranjos produtivos e de novas propostas de alavancagem do crescimento econômico, buscando conciliar melhor os objetivos de uma estrutura "global" que pouco atende às especificidades do "local".

Foi nesse contexto que se difundiram importantes discussões sobre a economia solidária no Brasil. A realidade da economia solidária perpassa a valorização das características locais dos empreendimentos e das comunidades nas quais estão inseridos, sejam elas econômicas, sociais ou culturais, ainda que seja no âmbito econômico que parte essencial dos empreendimentos solidários está centrada, como alternativa de geração de emprego e renda para grupos tradicionalmente marginalizados.

Contudo, gerar renda e estabelecer mecanismos de inclusão social constituem processos complexos, em especial quando se trata dos empreendimentos econômicos solidários (doravante EES), que centralizam as suas atividades sob a lógica autogestionária e, ao mesmo tempo, estão inseridas no ambiente econômico capitalista, o que faz da solidariedade um movimento muitas vezes contraditório para os trabalhadores na busca de possibilidades para sua sobrevivência.

Nesse tipo de empreendimento, apesar de os trabalhadores dominarem as técnicas de produção, estes, muitas vezes, não possuem conhecimento sobre gestão nem ferramentas que ajudam na tomada de decisões coletivas. Diferentemente de uma empresa capitalista tradicional, os gestores e membros desses empreendimentos são pessoas que, coletivamente, devem tomar decisões sobre todos os princípios que norteiam a economia solidária.

Para que as decisões coletivas se tornem efetivas e atendam às especificidades locais, a forma organizacional deve contemplar: incentivos para uma ampla participação dos membros dos EES nas diversas decisões que envolvem o seu dia a dia. É nesse campo de atuação que as incubadoras tecnológicas de cooperativas populares (ITCP's) atuam, tendo como um de seus objetivos fomentar a autogestão como modo de organização do trabalho frente às formas tradicionais, compostas por estruturas hierárquicas rígidas.

As incubadoras, portanto, acompanham grupos populares, ressaltando os valores da democracia, da participação e da cidadania que subsidiem o estabelecimento de novas relações de trabalho, da autogestão e de uma postura diferenciada perante o mercado. Ao mesmo tempo, a importância dessas incubadoras está no desenvolvimento de iniciativas que consolidam as 
Desenvolvimento local e economia solidária

relações entre a comunidade e a universidade, ou seja, que prezam uma maior interação entre o milieu local, a estrutura produtiva e gestionária típica de cada empreendimento e a comunidade acadêmica, contribuindo com as atividades de ensino, pesquisa e extensão.

Nesse sentido, o trabalho das ITCP's possui um caráter essencialmente extensionista, de valorização dos princípios participativos, de autogestão, emancipadores e de estabelecimento de interfaces entre a universidade e a comunidade, conferindo a esta melhores condições de estímulo e de exercício da cidadania. Na Universidade Federal de Ouro Preto - UFOP, está consolidada uma ITCP chamada "Incubadora de Empreendimentos Sociais e Solidários da UFOP" - INCOP, na qual se busca preservar os princípios da autogestão e o incentivo à participação inclusiva de grupos sociais marginalizados. Para refletir sobre as possibilidades de políticas de estímulo ao desenvolvimento econômico e social local e às trocas de experiências, este artigo se propõe a apresentar e discutir esse trabalho multicampi.

Lidando com grupos sociais bastante heterogêneos no que tange aos membros dos empreendimentos solidários incubados e com situações igualmente heterogêneas nos municípios que abrigam os seus campi (Ouro Preto, Mariana e João Monlevade), a INCOP tem se firmado como um importante canal de interlocução entre grupos sociais em situação de vulnerabilidade econômica e social e suas famílias; grupos sociais ainda pouco articulados ao mercado interno; instituições políticas (em especial, prefeituras); comunidade acadêmica (professores e alunos da UFOP); produtores e agentes / empresas financiadores e comunidade local, no cenário dos três campi.

Atualmente, estão incubados sete empreendimentos, sendo i) um grupo de agricultura familiar na cidade de Mariana-Minas Gerais (MG) chamado AHOBERO; ii) um grupo de assentados que fabrica artesanalmente utensílios com pedra-sabão donominado CAFUNDÃO, também na cidade de Mariana-MG; iii) a Associação de Usuários e Familiares da Rede de Saúde Mental (ASSUSSAM) de Ouro Preto-MG; iv) uma cooperativa de costura na cidade de João Monlevade-MG, chamada de UNI LABOR; v) uma cooperativa de catadores de material reciclável, a ATLIMARJOM; vi) uma associação de artesãos de nome SolidariArte; vii) uma ssociação de usuários de saúde mental (ASSUME) de João Monlevade.

Para a reflexão sobre essas experiências e sobre o contexto no qual elas emergem, este artigo foi dividido em quatro partes, excluindo esta introdução. Na primeira delas, será discutido o referencial teórico que ajuda no entendimento da débâcle da concepção mais intervencionista de planejamento e ascensão das estratégias de desenvolvimento local. Na segunda, será feita uma contextualização acerca da discussão sobre economia solidária no Brasil, que emerge com essa valorização do "local". Na terceira seção e em seus subitens, serão apresentados a INCOP e 
Desenvolvimento local e economia solidária

os seus empreendimentos. Na última, passam-se às considerações finais, seguidas da apresentação das referências bibliográficas.

\section{0 declínio das políticas de desenvolvimento regional e a ascensão do local: qual o papel da economia solidária?}

A década de 1950 foi muito produtiva, entre outros aspectos, por sua contribuição às denominadas Teorias do Desenvolvimento Regional, que balizaram muitas das estratégias de planejamento no Brasil e no mundo ${ }^{1}$. Esses trabalhos enfatizavam a necessidade de algum tipo de mecanismo dinâmico de autorreforço e eram resultantes de externalidades decorrentes da aglomeração industrial2 ${ }^{2}$ A estrutura teórica construída por esses estudiosos entende o crescimento regional como ocorrendo de forma não homogênea no espaço, mas em pontos ou polos de crescimento com intensidades variáveis, expandindo-se por diversos canais e com efeitos finais igualmente variáveis sobre toda a economia (CAVALCANTE, 2008).

Ademais, argumenta-se que as forças de mercado aumentam as desigualdades regionais e defende-se a intervenção do Estado para atenuar essas desigualdades. Tendo como base a aglomeração, Hirschman (1958) sustenta que o desenvolvimento econômico seria embaraçado "por uma série de círculos viciosos entrelaçados" e propõe que se procurem "pressões e processos de incentivo que farão eclodir e mobilizar o maior número possível de recursos escassos, tais como capital e atividade empreendedora". ${ }^{3}$

A aplicação desses modelos de cunho intervencionista na condução do crescimento econômico teve influência significativa até os anos de 1970. A análise dos mais importantes planos de desenvolvimento nacionais concebidos e executados até os anos 1980, no Brasil, mostra que os policy makers procuraram seguir as principais recomendações de políticas desses teóricos. Entretanto, cometeram uma série de erros na interpretação desses trabalhos. Por exemplo, a ênfase no processo de substituição de importações sem a diversificação de exportações, que comprometeu o desenvolvimento de longo prazo da economia nacional. Após esse período de forte intervenção estatal, seguiu-se uma onda liberal e, como consequência, ocorreram várias mudanças, inclusive no que diz respeito à interferência do mainstream econômico nas políticas de desenvolvimento regional.4

Percebe-se uma inflexão na forma de se pensar o papel do Estado, o que acaba se refletindo nas políticas de desenvolvimento regionais. Junto à "década perdida", ao aumento do desemprego e da informalidade e à precarização do emprego formal, tornou-se fundamental pensar formas alternativas de arranjos de produção, que congregassem elementos não somente econômicos, mas de preservação do conjunto vis-à-vis ao individual; de valorização das 
Desenvolvimento local e economia solidária

especificidades ao invés da padronização; de consideração do local como uma alternativa de fazer frente a um cenário adverso.

No Brasil, o declínio das estratégias de desenvolvimento regional enfrentou obstáculos de ordens internas e externas, catalisadas pelo cenário macroeconômico desfavorável do final da década de 1970. Tal inflexão acendeu os debates sobre a importância de se definirem estratégias de desenvolvimento local e, nesse contexto, emergiram as discussões sobre o papel de formas alternativas de produção e vivência, e, daí, a economia solidária.

No contexto em que se encontrava a economia nacional, o desafio agigantava-se em virtude da heterogeneidade socioeconômica das regiões brasileiras, pois as assimetrias em termos de crescimento econômico e de estrutura produtiva são históricas no quadro de formação econômica do Brasil. Sendo assim, trabalhar propostas de estímulo ao crescimento econômico em meio a um ambiente imerso em uma estrutura global passou a demandar um olhar regional/local. Para Diniz (2000), tal situação é paradoxal, pois torna a globalização e a regionalização, duas forças simultâneas e contraditórias, produto de um mesmo processo.

É nessa conjuntura, na qual o fortalecimento do desenvolvimento regional/local se faz necessário para conviver com estruturas globais, que emergem conceitos como Arranjos Produtivos Locais, Sistemas Locais de Inovação, Cooperação, Associação, Autogestão, entre outros. O desenvolvimento regional passa a ser visto como um processo complexo, que exige a interação de diversos agentes e relações, podendo ser representado pelo hexágono do desenvolvimento regional de Boisier (1996), constituído por seis fatores atuando simultaneamente: atores; cultura; entorno; instituições; recursos e os procedimentos.

Os atores ou agentes do desenvolvimento podem ser identificados pelas seguintes categorias: individuais, corporativos, coletivos e ethos. Em relação à cultura, dois são os elementos de interesse da sua incidência nos processos de desenvolvimento: o elemento competitivo/individualista e o elemento cooperativo/solidário (no primeiro caso, pode-se gerar crescimento, mas sem capacidade de gerar um verdadeiro desenvolvimento. No segundo caso, pode-se gerar equidade sem crescimento). No que se refere aos recursos, são quatro as categorias que interessam ao desenvolvimento: os tradicionais recursos materiais (recursos naturais, equipamentos de infraestrutura e recursos de capital); os recursos humanos, não apenas em quantidade, mas, sobretudo em relação à qualidade, vinculação regional e contemporaneidade; os recursos psicossociais, que adquirem importância cada vez maior e são associados a questões como a autoconfiança coletiva, a vontade coletiva, a perseverança, o consenso; e, em quarto lugar, os recursos de conhecimento.

No que concerne às instituições, Boisier (1996) ressalta que o que interessa no exame da institucionalidade regional é avaliar em que medida elas são flexíveis, velozes, inteligentes e 
Desenvolvimento local e economia solidária

virtuais. A flexibilidade é exigida para ajustar as instituições à realidade instável do ambiente; a velocidade se torna indispensável para entrar e sair de acordos e de redes e para aproveitar oportunidades num entorno dinâmico; a inteligência institucional diz respeito, principalmente, à capacidade de aprender e à capacidade de estabelecer articulações com outras instituições (formais ou informais); a virtualidade é uma condição para se proceder a operações ad hoc diante de algumas situações específicas, bem como para se configurar arranjos estratégicos. Por fim, o entorno, relaciona-se com tudo o que é externo à região ou ao local. Ele está configurado pela multiplicidade de organismos, sobre os quais não se tem controle (apenas capacidade de influência), mas com os quais a região como um todo se articula, necessariamente. Trata-se, fundamentalmente, do mercado em sentido lato, do Estado e do tecido de relações internacionais.

Os seis fatores que compõem o hexágono de Boiser (1996) podem ser identificados como determinantes do sucesso dos denominados Arranjos Produtivos Locais, Clusters e Distritos Industriais, que fazem uso da cooperação, da associação e das economias externas para fortalecer a posição das empresas que compõem essas formas organizacionais de produzir no mercado, sejam elas empresas pequenas, médias ou grandes. Nessa estrutura de interpretação do desenvolvimento regional/local, abre-se espaço para a inserção de abordagens alternativas de desenvolvimento, tais como a da economia solidária, que tem no cooperativismo, no associativismo e na autogestão os seus pilares de sustentação. Singer (2002) propõe a Economia Solidária como "conjunto de experiências coletivas de trabalho, produção, comercialização e crédito, organizada por princípios solidários que aparecem sob diversas formas: cooperativas e associação de produtores, empresas autogestionárias, bancos comunitários, clubes de troca e diversas organizações populares urbanas e rurais".

De acordo com Borinelli et al (2010), a economia solidária preza por um modelo de economia que visa aos aspectos sociais do conjunto, indo além do atendimento às necessidades materiais. Podem ser empreendimentos e projetos produtivos coletivos, cooperativas (populares, de agricultura familiar, de prestação de serviços, entre outras), redes de produção, comercialização e consumo, pequenos produtores que se unem para comprar e vender em conjunto. Também podem ser redes de comércio justo, incubadoras de empresas, clubes de troca e de microcrédito ou instituições financeiras voltadas para empreendimentos populares solidários, empresas autogestionárias, que dinamizam as economias locais, garantem trabalho e fomentam a economia local, tendo, ainda, como princípio, a preservação do meio ambiente.

O fortalecimento da economia solidária é, portanto, não apenas uma contribuição para o crescimento econômico, mas também um instrumento de desenvolvimento humano e de cidadania, como será visto na seção seguinte. Nesse ínterim, as incubadoras de tecnologia de 
Desenvolvimento local e economia solidária

cooperativas populares desempenham um importante papel como agentes impulsionadores desses princípios.

\section{Uma ferramenta do "Iocal": contexto e conceito da economia solidária}

A economia capitalista desdobra-se envolta a processos contraditórios. Singer (2002) aponta as diferenças entre as economias capitalista e solidária, cuja chave está no modo como as empresas são geridas. Este sistema utiliza-se da heterogestão e da administração hierárquica; em contraposição, na economia solidária, pratica-se a autogestão e a participação democrática.

Na economia capitalista, há assimetrias de poder nas relações capital-trabalho, exclusão de grupos de trabalhadores do mercado laboral e apropriação do excedente do trabalho daqueles que conseguem se inserir. Tais disparidades justificam as ações solidárias e também a união entre as partes menos favorecidas pelo sistema tradicional. A solidariedade vem aparecendo como um nexo possível, para além da exclusão, muito embora ela seja tecida no marco das condições atuais do modo de produção capitalista. Nesse sentido, necessário se faz apreendê-la em seu movimento contraditório, buscando especificar como a classe que vive do trabalho vem produzindo sua existência a partir desse nexo.

A economia solidária apresenta-se como alternativa de milhares de trabalhadores que buscam alterar suas condições de vida sob a forma de organização coletiva do trabalho, nas mais diversas regiões. Esse modelo tem sua fundamentação teórica em três elementos, o trabalho, a educação popular e o desenvolvimento. 0 trabalho tem, na economia solidária, um papel central em seu sentido ontológico, não como mera expressão do capitalismo que reduziu o trabalho ao emprego assalariado. 0 trabalho é a "expressão do produto da união entre a natureza e o homem, realizando um naturalismo no próprio homem e um humanismo na própria natureza" (MELO NETO, 2004, p. 70). É o trabalho na sua forma mais genuína, aquela expressa pela autogestão, na qual o trabalhador, ser livre e criativo, age na natureza transformando-a. 0 outro elemento é a educação popular, fundamental na consolidação da economia solidária como instrumento de transformação social.

Os grupos que se estruturam sob essa forma de organização produtiva têm como característica comum o trabalho coletivo, geralmente em situação econômica e produtiva extremamente frágil, isto é, o grau de desenvolvimento tanto dos meios e instrumentos de trabalho quanto da própria divisão do trabalho dentro dos grupos está aquém do dos outros setores econômicos. Tais grupos atuam nas mais diversas atividades que envolvem produções industriais e agrícolas. Porém, apesar da fragilidade estrutural, demonstram grande capacidade 
Desenvolvimento local e economia solidária

organizativa e criativa, sendo que a solidariedade e o trabalho coletivo têm contribuído para a sustentabilidade dos empreendimentos.

Para Razeto (2002), a maioria das organizações solidárias opera com recursos escassos, técnicas rudimentares, baixa tecnologia, saber fragmentário e capacidade de gestão apenas intuitiva. É, entretanto, por meio da força da solidariedade que esses poucos recursos se potencializam extraordinariamente. É a solidariedade a força que converte as experiências produtivas em ações viáveis e eficientes. Ações solidárias, no contexto dos ambientes organizacionais, podem ser desenvolvidas por todas as empresas e economias em nível global.

Lisboa (2001) aborda o surgimento da economia solidária a partir da crise no modo de produção capitalista. Para ele, a distribuição da riqueza não mais se dará por meio da participação no mundo do trabalho, e a perspectiva da economia solidária não se restringe à socialização da produção, mas a uma ampla visão de uma nova sociedade; o desenvolvimento ocorrerá a partir de experiências locais de autogestão que se potencializam quando apoiadas por complexos cooperativos e na sinergia entre empreendimentos solidários que cooperam entre si. O mercado será controlado pela sociedade; o ponto de partida, bem como o ponto de chegada, está no poder local.

O processo educativo vivenciado no movimento de economia solidária e no interior dos empreendimentos pode ser uma ponte, capaz de direcionar essas iniciativas para além do econômico. Pode ser também um instrumento privilegiado na emancipação dos setores que vivem do trabalho, articulando iniciativas produtivas, cujo aumento de sua capacidade política pode se dar a partir das redes solidárias, na perspectiva da reprodução ampliada da vida.

Essas práticas educativas, se contemplarem a autonomia e o protagonismo desses setores, podem ser o motor de um novo paradigma de desenvolvimento, aqui nomeado de desenvolvimento sustentável e solidário. Este é entendido como um processo de fomento de novas forças produtivas e de instauração de "novas relações de produção, de modo a promover um processo sustentável de crescimento econômico, que preserve a natureza e redistribua os frutos do crescimento a favor dos que se encontram marginalizados da produção social e da fruição dos resultados da mesma" (SINGER, 2004, p. 7).

\section{Empoderamento, autogestão e cooperação: a INCOP e seus empreendimentos em Ouro Preto, Mariana e João Monlevade}

Conforme já descrito, a INCOP, projeto de extensão multicampi que atua nos municípios mineiros de Ouro Preto, Mariana e João Monlevade, foi instituída em 2011, a partir dos anseios de alguns professores do Departamento de Engenharia de Produção da UFOP, que identificaram 
Desenvolvimento local e economia solidária

potencialidades em ampliar a interação entre os campi para ações extensionistas de geração de ocupação e renda. Em 2012, foram iniciadas as atividades na cidade de Ouro Preto e, em João Monlevade, foi iniciado o mapeamento das potencialidades locais, identificando possíveis grupos para serem incubados. No ano seguinte, deu-se início à incubação de sete empreendimentos nas áreas de material reciclável (catadores), costura, artesanato, agricultura familiar e saúde mental.

A metodologia de ensino utilizada na INCOP é baseada na pesquisa-ação e nos princípios do cooperativismo e da autogestão, sendo que a incubação é, basicamente, feita em quatro etapas: mapeamento (pré-incubação), implantação, desenvolvimento e desincubação. As equipes são compostas por alunos bolsistas e voluntários de várias áreas do conhecimento 5 , que acompanham os empreendimentos sob a orientação dos professores. São identificadas as demandas e possibilidades de cada empreendimento e, a partir da interação com o grupo, são desenvolvidas ações de assessoria, que vão desde as formações e cursos nos empreendimentos até resoluções de problemas, identificação e consolidação de parcerias, dentre outros.

A INCOP também participa do fórum regional de economia solidária, das redes sudeste (nível regional) e nacional de Incubadoras Tecnológicas de Cooperativas Populares, como parte de sua formação e ação política. São realizadas reuniões semanais em cada campus, nas quais são discutidas as ações semanais, divulgam-se as informações das ações junto aos empreendimentos e a realização de formações baseadas em textos acadêmicos. Ainda, semestralmente, é realizada uma reunião geral com todos os membros dos três campi para a socialização de informações, planejamento, avaliação, dentre outras necessidades.

Atualmente, a INCOP incuba três empreendimentos na região de Ouro Preto e Mariana, baseados na atividade artesanal, saúde mental e agricultura familiar (apresentados no item 4.1), e quatro empreendimentos nas áreas de saúde mental, artesanato, costura e catadores de material reciclável, em João Monlevade (apresentados no item 4.2).

\subsection{Os empreendimentos em Ouro Preto e Mariana: Associação de Hortifrutigranjeiros de Bento Rodrigues (AHOBERO), Cafundão, ASSUSSAM}

Pela sua relativa similaridade, os empreendimentos AHOBERO e CAFUNDÃO serão apresentados conjuntamente. Ambas são associações localizadas em dois subdistritos do município de Mariana (MG): Bento Rodrigues e Cachoeira do Brumado, respectivamente. A AHOBERO produz pimenta biquinho, da qual se fabrica a geleia de pimenta, e tem na agricultura familiar a fonte de emprego e renda dos seus associados. Atualmente, é composta por doze integrantes responsáveis por todo o procedimento de fabricação, que se dá, basicamente, pelo 
Desenvolvimento local e economia solidária

plantio/colheita, preparo das pimentas, cozimento, higienização e enchimento dos potes, rotulagem/embalagem e estocagem.

A INCOP incubou a AHOBERO em 2013, tendo como plano de atuação a assessoria técnica por meio de formações relacionadas à gestão administrativa. Os principais problemas encontrados foram: falta de adequação às normas da ANVISA; restrição em termos de acesso a Bento Rodrigues, o que eleva os custos de transporte e dificulta a manutenção e/ou ganho de novos mercados; falta de controle sobre custos e vendas; dificuldade em precificar o produto; baixo grau de escolaridade dos associados (o que dificulta o entendimento de conceitos básicos de gestão); restrito acesso à internet; dificuldade de atribuir valor qualitativo ao trabalho desenvolvido pelos associados.

A busca por soluções aos problemas apresentados se deu por meio de parcerias com o setor público e privado; com formações periódicas sobre gestão administrativa e gestão de negócios, financeira, de marketing e de pessoas. Além das formações relacionadas ao empreendimento propriamente dito, a INCOP buscou uma maior integração dos associados com a universidade, promovendo um curso de inclusão digital ocorrido na UFOP.

O outro empreendimento, o CAFUNDÃO, pertence a uma comunidade de assentados que, embora produza outro tipo de produto, passa por problemas semelhantes aos da AHOBERO. Ou seja, localizam-se em uma região de difícil acesso, seus associados possuem pouco ou nenhum grau de escolaridade, não há um controle sobre custos de produção, não há um plano de vendas continuadas (produz-se por encomenda), o acesso à internet é restrito e a comunidade conta com pouca infraestrutura básica. A associação tem na produção de artefatos de pedra-sabão (panelas, tachos, filtros, recipientes para temperos caseiros) sua principal fonte de renda, sendo essa atividade passada de geração a geração.

Diferentemente da AHOBERO, o associação CAFUNDÃO não possui estrutura física, e a fábrica funciona com uma infraestrutura bastante precária. As intervenções da INCOP tem se dado no sentido de buscar parcerias para a construção física da associação, divulgar o trabalho dos associados em encontros promovidos pela INCOP, apoiar os membros da associação em reivindicações junto ao poder público para a obtenção de melhorias para a comunidade; trabalhar a esfera administrativa do empreendimento, tentando mostrar aos associados aspectos relacionados à importância do controle de custos, da precificação dos produtos e da organização da fábrica.

No bojo desses princípios solidários, procedeu-se a incubação da Associação de Usuários e Familiares da Rede de Saúde Mental de Ouro Preto (ASSUSSAM-OP), cujo principal desafio é a reinserção dos usuários de serviço de saúde mental ao mercado de trabalho. Formada por cerca de 30 usuários dos Centros de Atenção Psicossocial (CAPS), I (saúde mental) e AD (álcool e 
Desenvolvimento local e economia solidária

drogas) e por familiares do CAPS I (infantil), a associação foi criada a partir de um projeto chamado "Oficina da Lua", por volta dos anos 2000, que promovia oficinas e cursos de patchwork, decoupage, cerâmica, tapete com retalhos e crochê em pano de prato. Até 2013, o projeto ficou inativo, mas conseguiu outro apoio de um edital do Ministério da Saúde, e foi nesse período que a ASSUSSAM procurou a INCOP para auxiliá-la a atuar como um empreendimento solidário, por meio da promoção de novos cursos, visitas técnicas, palestras, capacitações e do auxílio nas pendências burocráticas.

Os usuários do serviço de saúde mental ainda lutam contra o preconceito e a exclusão, seja da sociedade ou do poder público. A ASSUSSAM surge como uma ajuda no enfrentamento dessa realidade. Por meio da produção, da rede de trocas e da definição de mecanismos de geração de trabalho e renda, espera-se que seus membros adquiram e repassem conhecimentos, além de serem estimulados a acreditar em seu potencial e no da própria associação.

\subsection{Os empreendimentos da INCOP em João Monlevade}

A UNILABOR é uma cooperativa produtora de uniformes industriais, localizada na cidade de João Monlevade - MG. Composta unicamente por mulheres, foi fundada em 1969 a partir de um clube de mães, já tendo somado mais de 75 cooperados ao longo de sua história. Em seu tempo de maior produção, a cooperativa contou com mais de 30 associados, restando, atualmente, apenas seis mulheres vinculadas formalmente à associação.

Em março de 2012, a cooperativa UNILABOR foi incubada pela INCOP. A partir daí, foram realizadas visitas semanais à cooperativa. Antes do expediente, o grupo discute o cenário atual da cooperativa, como finanças, pedidos e demandas. Essa metodologia por si só é um ganho da incubação, pois foi estabelecida após numerosas frustrações no diálogo do processo de incubação. Em um diagnóstico inicial, foram levantados os seguintes problemas: a) falta de conhecimento sobre técnicas de gestão; b) dificuldades na comunicação entre as cooperadas; c) dificuldades com técnicas de costura; d) falta de participação das cooperadas nas decisões. ${ }^{6}$

A INCOP buscou, de maneira dialógica de organização das ações, oferecer cursos de associativismo e cooperativismo; organizar reuniões periódicas e um seminário sobre qualidade, tendo em vista os diversos problemas de qualidade de produto levantados. Somam-se a essas três outras atividades do cotidiano, relacionadas à própria gestão da qualidade, gestão de custos e fomento à participação das cooperadas no Fórum Mineiro de Economia Solidária e nas comemorações municipais no dia internacional do cooperativismo. No entanto, ainda evidenciase que as cooperadas estão distantes de um processo real de empoderamento e de ampla participação na gestão da cooperativa. 
Desenvolvimento local e economia solidária

Outro empreendimento incubado em João Monlevade é a Associação de Trabalhadores de Limpeza e Materiais Recicláveis de João Monlevade - ATLIMARJOM. Fundada em 2002, a partir da iniciativa de alguns catadores que atuavam no lixão de João Monlevade - MG, em parceria com a prefeitura, a qual, por meio do sistema de comodato, cedeu um galpão para a sede, assumindo o custeio de algumas despesas como água, luz e vale-transporte. Em contrapartida, os catadores se organizaram para realizar o trabalho na maior escala possível, a fim de diminuir o lixo enviado ao "novo" aterro.

A associação é composta, em média, por 20 catadores. São constantes os problemas de relacionamento interpessoal, falta de compromisso com o trabalho, dependência química, alta rotatividade de associados e, consequentemente, baixa produtividade, o que tem prejudicado o seu desenvolvimento. Em 2013, a INCOP iniciou suas atividades junto à associação. Depois de formalizada a parceria, a incubadora se deparou com várias barreiras no início dos trabalhos junto à organização.

A INCOP acompanha as ações desenvolvidas pelos associados em todos os setores da organização, desde a captação de material, triagem, processamento e estocagem até o controle burocrático, as vendas e demais atividades administrativas. A partir disso, a incubadora identificou os principais gargalos produtivos da associação. Foi elaborado um plano de ação baseado na economia solidária, cooperativismo e em ferramentas da engenharia de produção que poderiam proporcionar soluções. Apesar dessas ações e de alguns resultados positivos, a associação ainda tem dificuldade de consolidar e manter algumas ações delimitadas, muitas vezes, devido à rotatividade dos associados, a problemas de dependência química e de traumas de experiências malsucedidas que eles enfrentam, a interesses políticos, dentre outros.

Outro grupo incubado pela INCOP-JM, que não apresenta muita diferença em suas demandas para seu fortalecimento, é a Associação de Artesãos SolidariArte, incubada desde 2013. O grupo é composto por associados de diferentes faixas etárias, localidades e temperamentos, o que torna o coletivo bastante heterogêneo, gerando opiniões divergentes no trabalho cotidiano, falta de organização interna e problemas de comunicação entre os membros e, consequentemente, dificuldade de planejar suas atividades e tomar decisões.

Assim, a INCOP trabalhou com os associados a possibilidade de criação de uma estrutura interna formalizada, estabelecendo cargos representativos e funções, que beneficiariam a comunicação e a organização. Os associados discutiram novas ideias que, por sua vez, converteram-se em soluções para problemas, desde os mais simples aos mais complexos, enfrentados até aquele momento, como a comunicação, a participação nas atividades da associação, a falta de dinheiro em caixa, dentre outros, o que resultou na consolidação de um estatuto, de um regimento interno e de uma melhor convivência. Nos aspectos técnicos, foram 
Desenvolvimento local e economia solidária

oferecidas formações à associação, como cursos de economia solidária, associativismo e cooperativismo, precificação de produtos e qualidade no atendimento ao consumidor. Atualmente, a SolidariArte procura consolidar-se no mercado de João Monlevade e região, onde a tradição artesanal, no geral, ainda é incipiente.

Finalmente, o quarto empreendimento incubado em João Monlevade é a ASSUME. Assim como no caso da ASSUSSAM, a economia solidária tem favorecido a inclusão produtiva e social de pessoas marginalizadas da sociedade, como os usuários dos serviços públicos de saúde mental. Criada em 1996, com atendimento de, em média, 30 usuários por dia, no início de 2013, começou a ser incubada pela INCOP. Porém, há vários problemas de âmbito estrutural, organizacional e, até mesmo político, para que as ações se concretizem.

A ASSUME é constituída pelos usuários da saúde mental e seus familiares, oriundos do Centro de Atenção Psicossocial II de João Monlevade. Toda a diretoria da associação é formada pelos usuários, para facilitar a emancipação. Com o apoio da prefeitura, foi feito um convênio, renovado anualmente, para manutenção do Espaço de Convivência, local das atividades laboterapêuticas e das atividades artesanais, que auxiliam na socialização, na coordenação motora e na complementação de renda.

O processo de incubação foi iniciado em 2013, por meio de visitas para caracterização do grupo e de suas demandas. Com a aprovação dos associados, foram realizados os cursos de associativismo, cooperativismo e economia solidária, precificação, Excel e marketing. Nesse período, foi escrito pela INCOP, juntamente com a ASSUME, um projeto intitulado "Mentes Brilhantes", para um edital do Ministério da Saúde. Aprovado no final de 2013, os recursos foram canalizados para a consolidação e ampliação de ações para os usuários. Nessa oportunidade, o empreendimento conseguiu aproximar-se da Secretaria de Saúde Municipal e do CAPS, estreitando os laços para que o envio da proposta fosse feito.

Para ampliar as atividades da ASSUME, o grupo de trabalho da INCOP tem organizado ações interativas, integrativas e motivacionais internas, além de atividades externas, como a marcha da luta antimanicomial, em Belo Horizonte, e visitas a outros empreendimentos que trabalham com usuários de saúde mental na região. Apesar das ações citadas, ainda existem entraves, não só pelo perfil do empreendimento, como também pela relação com os parceiros da associação, como a prefeitura, a secretaria de saúde e o CAPS.

\section{Considerações finais}

A necessidade de se pensar as relações de produção para além das exigências do sistema capitalista somada à crise dos Estados nacionais, cujos efeitos vieram à tona para os 
Desenvolvimento local e economia solidária

países subdesenvolvidos a partir da década de 1980, influenciaram as discussões sobre as estratégias e novos rumos para acelerar o desenvolvimento.

Para dar conta do conjunto das transformações "globais" típicas desse contexto e que condicionam os mecanismos de tomada de decisão por parte dos gestores públicos, torna-se fundamental pensar em ações "locais", de forma a atenuar os impactos dessas mudanças e a tornar possível a melhoria da qualidade de vida, aumentar a integração social (principalmente de grupos marginalizados), reconstituindo o sentido de cidadania e pertencimento do local.

Considerar as particularidades e demandas do "local" reforça a sua valorização, facilita a difusão do conhecimento tácito, fortalece os laços de relações concretas, socialmente construídas e territorialmente localizadas. A promoção do desenvolvimento local em um país com as dimensões e a heterogenia socioeconômica do Brasil passa por inúmeros desafios. Além disso, deve-se considerar que até mesmo os instrumentos utilizados para tal são recentes no contexto da economia brasileira, como é o caso da economia social e solidária. Isso porque o debate teórico sobre o tema se acentuou nos anos 1990, quando o Brasil enfrentou uma série de transformações sociopolíticas acentuadas pela redemocratização, crises federativas que afetaram os municípios, amadurecimento dos primeiros efeitos das mudanças trazidas pela Constituição de 1988 e intensificação do processo de reestruturação produtiva, que culminou em altos índices de desemprego e no aumento da informalidade.

A economia solidária seria, portanto, uma das vias possíveis no âmbito do caminho alternativo, pois tem como princípio a cooperação, a associação e a autogestão. Pode-se dizer que as mesmas ferramentas que se utilizam para fortalecer a cooperação e a associação de empresas não autogestionárias podem, também, ser utilizadas nos empreendimentos sociais e solidários, porém, tendo como pilar central, a autogestão. A gestão solidária constitui uma importante ferramenta, não apenas de crescimento e desenvolvimento econômico local, mas de desenvolvimento humano, por abarcar extratos da população que não conseguem se enquadrar nas regras dos modelos de racionalidade econômica. Esse é o caso, por exemplo, dos agricultores familiares, dos artesãos, dos catadores e dos usuários de saúde mental.

As atividades baseadas na economia solidária ainda deparam-se com grandes entraves. No entanto, se tem buscado amadurecer cada vez mais essa proposta. Um bom exemplo disso tem sido a criação das incubadoras universitárias, tal como a INCOP. Considera-se que o trabalho desenvolvido por esse tipo de instrumento tem resultados bastante significativos no âmbito local, mesmo defronte de vários percalços encontrados, sendo os principais a escassez de recursos e os problemas de ordem estrutural encontrados nos empreendimentos (o analfabetismo ou semianalfabetismo é um exemplo). Reitera-se a importância de políticas públicas que fortaleçam esse segmento, como também a redução da lacuna existente entre 
Desenvolvimento local e economia solidária

universidade e as comunidades nas quais estão inseridas.

\section{Referências}

BOISER, S. Em Busca do Esquivo Desenvolvimento Regional: Entre a Caixa-preta e o Projeto Político. Planejamento e Políticas Públicas, n. 13, jun. de 1996.

BORINELLI, B. Economia solidária em Londrina: aspectos conceituais e experiência institucional. Londrina: UEL, 2010.

CAVALCANTE, L. R. Produção Teórica em Economia Regional: Uma Proposta de Sistematização. Revista Brasileira de Estudos Regionais e Urbanos, v. 02, p. 9-32, 2008.

DINIZ, C. C. Global-Local: Interdependências e Desigualdade ou Notas para uma Política. Contrato BNDES/FINEP/FUJB Arranjos e Sistemas Produtivos Locais e as Novas Políticas de Desenvolvimento Industrial e Tecnológico. Estudos Temáticos. Nota Técnica 9, 2000.

FUJITA, M.; KRUGMAN, P.; VENABLES, A. The spatial economy: cities, regions, and international trade. Cambridge, MA: MIT, 1999

HIRSCHMAN, A. O. The strategy of economic development. New Haven: Yale University Press, 1958.

ISARD, W. Methods of regional analysis: an introduction to Regional Science, Cambridge: MIT, 1960.

LECHAT, N. M. P. As Raízes Históricas da Economia Solidária e seu aparecimento no Brasil. In: II Seminário de incubadoras tecnológicas de cooperativas populares. Unicamp, São Paulo, 2002.

LISBOA, A. de M.. A socioeconomia solidária diante da grande transformação. Revista de Ciências Sociais, n. 159, 2001.

LÖSCH, A. The economics of location. New Haven: Yale University, 1954.

MELO NETO, F. P. Empresas socialmente sustentáveis: o novo desafio da gestão moderna. Rio de Janeiro: Qualitymark, 2004.

RAZETO, L. Entrevista a Neticoop (Rede da Confederação Uruguaia de Entidades Cooperativas). Disponível em: <http://neticoop.org.uy >. Acesso em: 07 out. 2014.

SINGER, P. Desenvolvimento capitalista e desenvolvimento solidário. In: Estudos Avançados. 2004. v. 18, n. 51, p. 7-22.

SINGER, P. Introdução à Economia Solidária. São Paulo: Editora Fundação Perseu Abramo, 2002.

\footnotetext{
${ }^{1}$ Fazendo uma breve recapitulação teórica, o desenvolvimento regional pode ser interpretado a partir de duas vertentes. A primeira remete aos modelos clássicos de localização da firma (Von Thunen quando da publicação do seu "O Estado Isolado", datado de 1826, Alfred Weber com sua obra de 1909 "Teoria da Localização das Indústrias", Walter Christaller que escreveu, em 1933, "Os lugares centrais no Sul da
} 
Alemanha" e Auguste Lösch, que publicou, em 1940, "A Ordem Espacial da Economia"). Na segunda, temos Walter Isard propondo uma linha de pensamento chamada de "Regional Science". As hipóteses que permeiam essa estrutura teórica são aquelas que caracterizam as estruturas de mercado em concorrência perfeita, quais sejam: o comportamento otimizador dos agentes econômicos maximizadores de lucros e minimizadores de custos; tecnologia de produção facilmente reprodutível e tendência ao equilíbrio dos mercados.

2 Embora essas teorias tenham sido disseminadas a partir dos anos 1950, suas origens se dão com Alfred Marshall em 1890, quando considera, em seus estudos, do comportamento da firma às externalidades pecuniárias e tecnológicas e com Joseph Alois Schumpeter, em 1911, que analisa o papel das inovações tecnológicas na dinâmica capitalista. Podem ser citados como representantes da segunda vertente mencionada: François Perroux, com sua obra "Teorias dos Polos de Crescimento" (1955); Gunnar Myrdal, com a "Teoria Econômica e Regiões Subdesenvolvidas" (1957); e Albert Hirschman, que escreveu "A Estratégia de Desenvolvimento Econômico" (1958).

${ }^{3}$ Esse teria sido o argumento básico para a defesa dos planos de desenvolvimento que ocorreram nos países “de terceiro mundo", inclusive no Brasil, na gestão de Juscelino Kubitschek (1956-1960).

${ }^{4}$ No âmbito das teorias de crescimento regional, tornou-se referência, nos anos 2000, a obra de Krugman, Fujita e Venables: "The Spatial Economics", que representou a retomada das hipóteses dos modelos clássicos de interpretação da dinâmica regional (Cavalcante, 2008), explicando a micro-organização espacial dos agentes. 0 comportamento espacial dos agentes é retratado por meio de um modelo de equilíbrio geral, que se caracteriza pela existência de um equilíbrio instantâneo entre oferta e demanda, pela confirmação das expectativas, pelos fatores de produção serem todos alocados e, consequentemente, todos os mercados estarem em equilíbrio. Esses resultados seriam possíveis porque se consideram todas as firmas móveis, as tecnologias homogêneas e que não há nenhuma aparente economia externa à firma.

5 Letras, Direito, Serviço Social, Economia, Engenharia de Automação, Engenharia de Computação, Engenharia de Produção, Engenharia Elétrica, Jornalismo e Sistemas de Informações.

6 Percebe-se que os problemas diagnosticados não diferem muito de diversos outros casos de empreendimentos de economia solidária. Neste relato, será feito um recorte nas ações que visaram ao empoderamento da cooperativa, pois, no início da incubação, foi identificado que a maioria dos processos de tomada de decisões não passava por toda a cooperativa. Não havia a prática de gestão coletiva, pelo contrário, as responsabilidades eram assumidas pela presidente, de forma que o desenvolvimento do grupo se deu em níveis diferentes para cada cooperada.

\section{Local development and solidarity economy: the experience of the Solidarity Enterprises Incubator UFOP (INCOP)}

\begin{abstract}
This paper aims to discuss some of the obstacles and opportunities for local development strategies developed by the Solidarity Economy Enterprises (SEE) incubator. These initiatives are important to strengthen relations between the university and the community, which they are inserted. In addition, the SEE objectives to expand the interaction between marginalized social groups and their local environment, emphasizing the principles of joint participation, self-management, empowerment and emancipation. Conceptual elements were rescue from local development and solidarity economy. Finally, a case study of INCOP - UFOP was presented.
\end{abstract}

\section{Keywords}

Local development; Solidarity economy; INCOP UFOP.

\section{Desarrollo local y economía solidaria: la experiencia de la Incubadora de Empresas Solidarias de la UFOP (INCOP)}

\section{Resumen}

El objetivo de este trabajo es discutir algunos de los obstáculos y de las oportunidades de estrategias de desarrollo local a partir de los roles de las incubadoras de emprendimiento solidario. Tales iniciativas son importantes para fortalecer las relaciones entre la universidad y la comunidad en la cual está inserida. Además, objetiva mayor interacción entre los grupos sociales marginados y su ambiente local, valorizando a los principios de la participación, de la autogestión, autonomía y emancipación. Fueron rescatados elementos conceptuales del desarrollo local y la economía solidaria y, finalmente, presentado el estudio de caso del proyecto de extensión de la INCOP - UFOP..

\section{Palabras clave}

Desarrollo local; Economía solidaria; INCOPUFOP. 
Desenvolvimento local e economia solidária

Original submetido em: 8 jun. 2015

Aceito para publicação em: 28 jun. 2015

Sobre os autores:

\section{Wagner Ragi Curi Filho}

Professor do Departamento de Engenharia de Produção, Instituto de Ciências Exatas e Aplicadas, Universidade Federal de Ouro Preto (UFOP), Campus João Monlevade. Coordenador Geral da INCOP- UFOP.

\section{Jean Carlos Machado Alves}

Professor do Departamento de Engenharia de Produção, Instituto de Ciências Exatas e Aplicadas, Universidade Federal de Ouro Preto(UFOP), Campus João Monlevade. Coordenador da Rede Sudeste de ITCP's.

\section{Fernanda Faria Silva}

Professora do Departamento de Ciências Econômicas e Gerenciais, Universidade Federal de Ouro Preto (UFOP), Campus Mariana. Pesquisadora do LEMTe-CEDEPLAR, Universidade Federal de Minas Gerais (UFMG). Visiting Scholarship Student na Universidad de La Laguna, Spain (2009-2010).

\section{Francisca Diana Ferreira Viana}

Professora do Departamento de Engenharia de Produção, Universidade Federal de Ouro Preto (UFOP), do Mestrado em Saúde e Nutrição do Departamento de Nutrição Clínica e Social e dos cursos de bacharelado em Administração Pública e licenciatura em Geografia do Centro de Educação Aberta e a Distância (CEAD/UFOP). 